\title{
RANCANG BANGUN SISTEM INFORMASI PENGGAJIAN DENGAN IMPLEMENTASI METODE WATERFALL
}

\author{
Nurul Afni[1], Roida Pakpahan ${ }^{[2]}$, Astri Rezky Jumarah ${ }^{[3]}$ \\ Program Studi Sistem Informasi[1][2][3] \\ Universitas Bina Sarana Informatika[1][2][3] \\ www.bsi.ac.id ${ }^{1][2][3]}$ \\ nurul.nrf@bsi.ac.id[1]; roida.rkh@bsi.ac.id[2]; astri.rezky07@gmail.com[3]
}

\begin{abstract}
Salary is one of the motivations of employees in a company. With a salary can increase morale and show expertise to get a salary. The manual calculation system carried out at the National Secretariat of the Indonesian Architects Association needs to be done several improvements, especially on a system that must switch from manual to a better digital system. This is because the process that is being undertaken is less effective because it is still wasteful of paper (print media) and not a bit of a miscalculation in managing salaries until the salary archiving is still scattered so it is difficult both in the search and monitoring of employee data again. The purpose of this research is to assist agencies in designing and implementing a computerized payroll system as one of the solutions to the problems faced today. The results of the researchers made using a web-based payroll system with the help of tools to use use diagrams, activity diagrams, ERD, LRS and web prototypes that will be used to smooth the salary process to save more paper and quick and precise calculations.
\end{abstract}

Keywords: Payroll, salary design, salary information system

Intisari- Gaji merupakan salah satu motivasi karyawan dalam suatu Perusahaan. Dengan adanya gaji dapat meningkatkan semangat dan menunjukkan keahliannya untuk mendapatkan suatu gaji. Sistem perhitungan manual yang dilakukan pada Sekretariat Nasional Ikatan Arsitek Indonesia perlu dilakukan beberapa perbaikan terutama pada sistem yang harus beralih dari manual ke sistem digital yang lebih baik. Hal ini dikarenakan pada proses yang sedang dijalani kurang efektif karena masih boros kertas (media cetak) dan tidak sedikit salah perhitungan dalam mengelola gaji hingga dalam pengarsipan gaji masih tercecer sehingga sulit baik dalam pencarian maupun monitoring data karyawan kembali. Tujuan penelitian untuk membantu instansi dalam merancang dan menerapkan sistem penggajian yang terkomputerisasi sebagai salah satu solusi terhadap masalah yang dihadapi saat ini. Hasil yang peneliti buat menggunakan sistem penggajian berbasis web dengan dibantu alat pendukung use case diagram, activity diagram, ERD, LRS dan prototype web yang akan digunakan untuk kelancaran proses gaji hingga lebih hemat kertas dan perhitungan yang cepat dan tepat.

Kata Kunci: Penggajian, Rancang Bangun gaji, Sistem informasi gaji

\section{PENDAHULUAN}

Informasi merupakan kebutuhan penting dalam sebuah perusahaan, lembaga, dan instansi lainnya. Menurut Darmawan dan Fauzi dalam (Imaniawan, 2017), "Sistem informasi merupakan kumpulan dari sub-sub sistem yang saling berhubungan satu sama lain, dan bekerja sama secara harmonis untuk mencapai suatu tujuan".

Dengan menggunakan system informasi yang terkomputerisasi maka pengguna system bisa mendapatkan informasi yang akurat secara efektif dan efisien. Salah satu informasi yang penting dalam sebuah instansi adalah informasi tentang kepegawaian dan penggajian. Menurut Mulyadi dalam (Danke, 2015), "Penggajian adalah pembayaran atas penyerahan jasa yang dilakukan oleh karyawan administrasi atau yang mempunyai jenjang jabatan yang pada umumnya dibayarkan secara tetap per bulan."

Sekretariat Nasional Ikatan Arsitek Indonesia pada proses penggajian masih dikerjakan secara manual, hal itu bisa mengakibatkan menumpuknya file-file dan mempunyai kemungkinan untuk hilang dan akan memakan waktu yang cukup lama untuk mencarinya kembali. Sehubungan dengan kondisi tersebut, maka diperlukan suatu system penggajian karyawan berbasis web. Dengan system pencatatan data dan monitoring yang dilakukan secara realtime. Sistem administrasi penggajian merupakan proses yang menentukan tingkat penggajian pegawai, memantau, atau mengawasi, mengembangkan serta mengendalikan gaji pegawai

Tujuan penelitian ini adalah untuk mengetahui bagaimana merancang dan menerapkan system penerimaan gaji yang terkomputerisasi sebagai salah satu solusi 
terhadap masalah yang dihadapi instansi serta membantu meningkatkan efisiensi dalam merekap maupun mengarsipkan laporan penggajian yang efektif menggunakan metode waterfall.

\section{BAHAN DAN METODE}

Dalam menyusun perancangan system informasi pengolahan data dapat menggunakan berbagai metode penelitian, metode penelitian yang dibutuhkan harus berhubungan erat dengan prosedur yang ada. Adapun metode penelitian yang digunakan adalah menggunakan metode pengembangan perangkat lunak Waterfall. Menurut Rosa A.S \& M.Shalahuddin dalam (Komalasari, 2018), "Model Pengembangan Perangkat Lunak atau yang biasa disebut System Development Life Cycle (SDLC), adalah proses mengembangkan atau mengubah suatu system perangkat lunak dengan mengembangkan sistemsistem perangkat lunak sebelumnya".

Rancangan penelitian dengan metode waterfall ini dimulai dari analisa kebutuhan yaitu membuat gambaran web pada kebutuhan instansi untuk mengolah gaji, kemudian desain dimana pada proses ini mendesain rancangan ERD, LRS, database serta UML dan terakhir pengujian untuk memastikan apakah web yang dihasilkan sesuai dengan kebutuhan dan memastikan keluaran yang dihasilkan.

Sumber data didapat dari data sekunder, dimana data yang diperoleh dari hasil wawancara dengan pimpinan instansi yang meliputi struktur organisasi instansi hingga sistem dan prosedur penggajian yang sedang berjalan hingga saat ini.

Teknik pengumpulan data berasal dari observasi dimana pengumpulan data ini mengamati secara langsung prosedur sistem penggajian pada instansi sekretariat nasional ikatan arsitek indonesia, kemudian wawancara yang dilakukan secara langsung kepada kepala instansi hingga pengumpulan dokumen yang terkait dan terakhir studi pustaka yaitu menelaah terhadap buku-buku atau referensi jurnal sebelumnya.

Sekretariat Nasional Ikatan Arsitek Indonesia merupakan suatu lembaga organisasi yang menampung para arsitek profesional yang sudah diakui dan hasil kinerjanya. Analisa sistem penggajian yang berjalan sebagai berikut:

\section{Proses Rekap Absensi}

Karyawan yang masuk dan pulang kerja setiap hari absen menggunakan input excel. Penginputan rekapitulasi lalu setelah itu dijadikan arsip absensi.

\section{Proses Perhitungan Gaji}

Penghitungan gaji karyawan dilakukan oleh bagian keuangan dengan membaca atau mengarsip rekapitulasi absensi karyawan. Setelah gaji dihitung bagian keuangan melihat arsip kasbon karyawan untuk menghitung gaji net . Kemudian gaji total dicetak dan dibuat rekapitulasinya oleh bagian keuangan dan selanjutnya meminta persetujuan kepada ketua umum untuk disetujui. Dari persetujuan ketua umum , rekapitulasi yang sudah dicetak dikembalikan lagi ke bagian keuangan untuk diarsipkan, begitu dengan data-data gaji karyawan juga disimpan dalam arsip gaji karyawan.

\section{Proses Pembayaran Gaji}

Berdasarkan arsip rekapitulasi yang telah disetujui ketua umum, bagian keuangan membayar gaji kepada karyawan, bagian keuangan membayar gaji kepada karyawan dengan memberikan slip gaji karyawan. Slip gaji tersebut berisi rincian detail gaji yang diterima karyawan yang bersangkutan dan bagian keuangan juga memberikan tanda terima gaji karyawan untuk ditanda tangani sebagai bukti pembayaran dan setelah ditanda tangani, tanda terima tersebut di arsipkan.

\section{Laporan}

Bagian keuangan membuat laporan gaji dan melihat slip gaji karyawan yang sudah ditanda tangani oleh karyawan dan ditujukan kepada ketua umum sedangkan copy-an diarsipkan.

Dilihat dari proses yang ada maka permasalahan yang terjadi adalah tidak adanya teknologi yang canggih untuk mempermudah dalam proses penggajian. Data gaji karyawan masih berbentuk kertas dan masih kurangnya tempat penyimpanan laporan gaji karyawan.

Pemecahan masalah dari proses perhitungan hingga pengarsipan gaji yang manual adalah menjadi berbasis website. Dengan adanya system penggajian berbasis web diharapkan mampu membantu bagian keuangan dalam merekap penghitungan gaji setiap karyawan hingga penyimpanan melalui database agar dapat mengurangi resiko kehilangan data. System berbasis website merupakan system online yang dapat diakses secara langsung oleh karyawan, untuk melihat data gaji karyawan tanpa harus mengunjungi bagian keuangan.

\section{HASIL DAN PEMBAHASAN}

Kebutuhan Sistem yang akan diperlukan dan yang digunakan dalam pembuatan sistem penggajian karyawan ini, terdiri dari beberapa bagian, baik aplikasi maupun pengguna dari aplikasi sistem penggajian karyawan ini, kebutuhan sistem itu diantaranya :

A. Kebutuhan Pengguna

Pengguna bagi sistem penggajian karyawan merupakan Admin atau bagian Keuangan yang 
diberi hak akses untuk memakai sistem penggajian. Sistem penggajian tidak memberi batasan pengguna lain seperti staff bagian lain untuk mengakses sistem. Pengelolaan pengguna diserahkan pada bagian Keuangan.

Kebutuhan pengguna Sistem penggajian karyawan akan dibagi menjadi 4 tipe yang konfigurasinya diatur oleh Bagian Keuangan sendiri yaitu :

1. Bagian Keuangan

a. Melakukan penginputan data karyawan

b. Mengeluarkan gaji dan membuat slip gaji

c. Melakukan pengolahan user

\section{Karyawan}

a. Melakukan absen

b. Melihat laporan kehadiran karyawan

c. Melihat laporan lembur karyawan

d. Melihat potongan gaji karyawan

e. Menerima gaji dan melihat slip gaji

f. User biasa (bukan Database dan security admin)

3. Ketua Umum

a. Melihat data karyawan

b. Melihat laporan data kayawan

c. Melihat laporan kehadiran karyawan

d. Melihat laporan lembur karyawan Melihat laporan potongan gaji karyawan

Kebutuhan Pengguna Sistem penggajian pada bagian karyawan :

1. Menginput data username

2. Menginput kartu absen untuk dijadikan data arsip

Kebutuhan Pengguna Sistem penggajian pada Keuangan :

1. Melakukan perhitungan gaji perbulan

2. Melakukan rekapitulasi gaji karyawan

B. Kebutuhan Sistem

1. Setiap pengguna sebelum masuk ke sistem penggajian karyawan, akan login terlebih dahulu sesuai aksesnya masing-masing.

2. Setelah karyawan memberikan id card kepada bagian keuangan akan menginput dan melakukan rekapitulasi penggajian karyawan.

3. Pengguna Bagian Keuangan dapat mengelola seperti mengubah, menambahkan dan menghapus data karyawan.

Berikut rancangan Diagram use case, Activity diagram, ERD, LRS dan Prototype Web Penggajian Usulan.
1. Rancangan Diagram Use Case

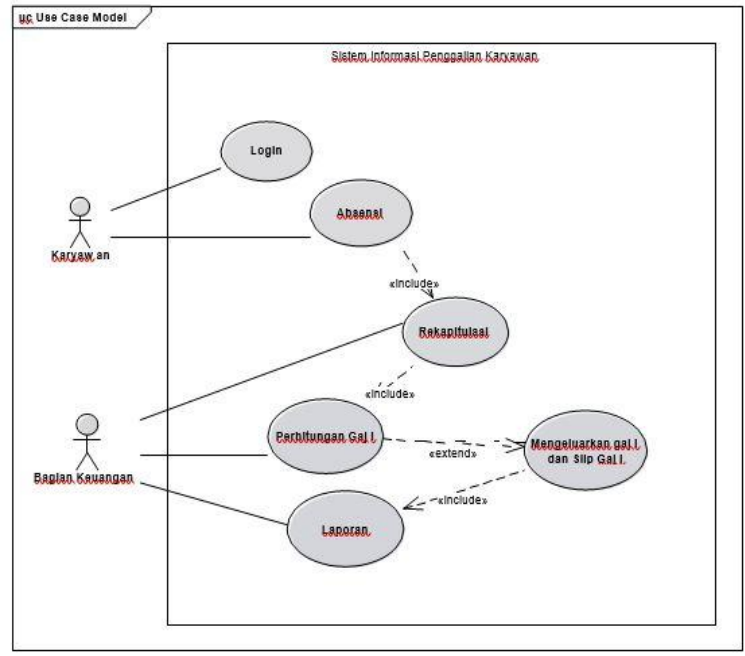

Sumber: Penelitian (2019)

Gambar1. Use Case Sisfo Penggajian

2. Activity Diagram Admin

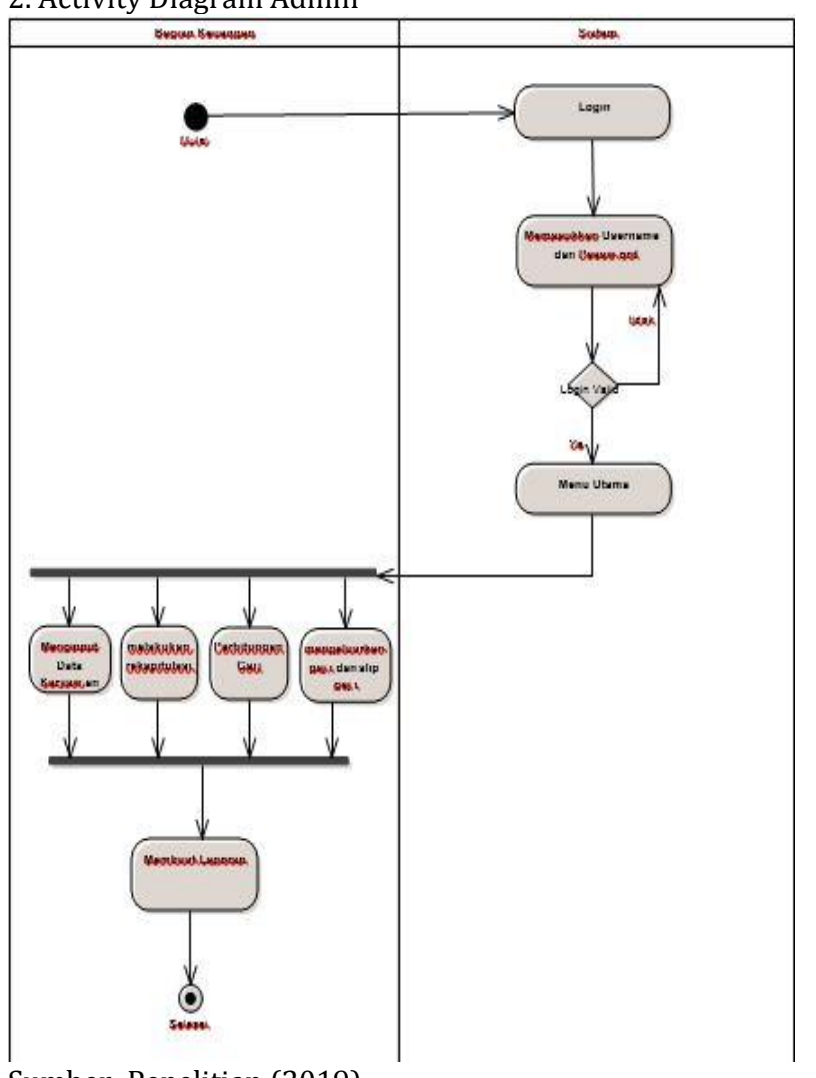

Sumber: Penelitian (2019)

Gambar2. Activity Diagram Admin 
3. Activity Diagram Karyawan

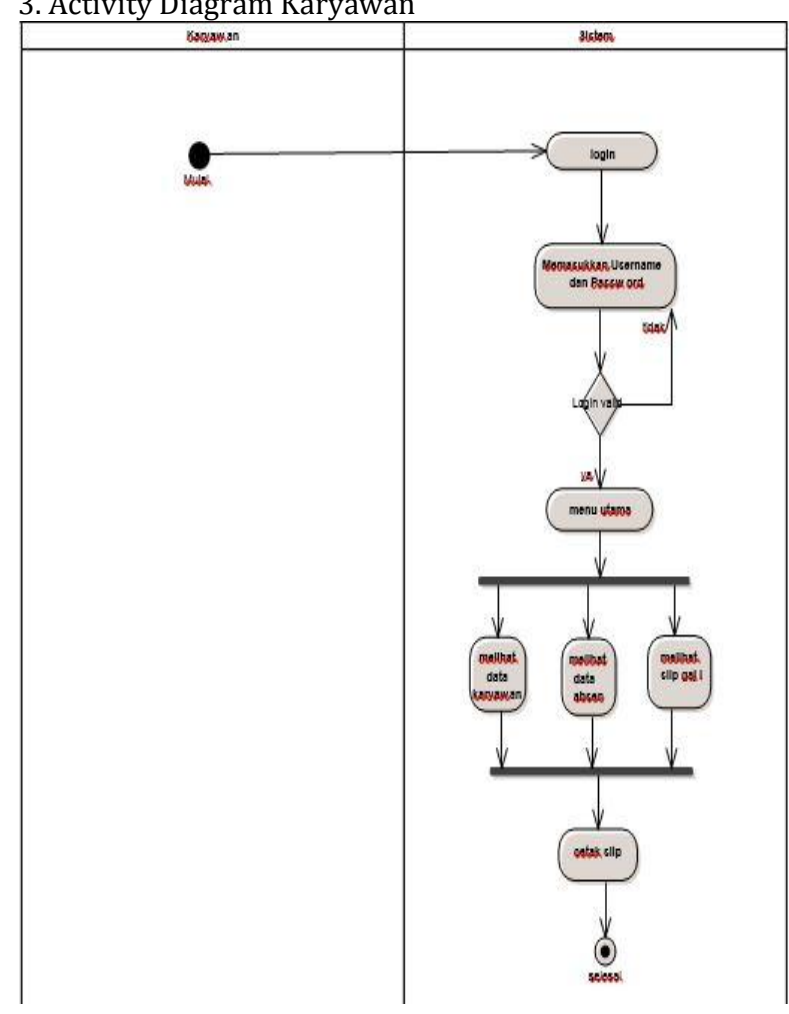

Sumber: Penelitian (2019)

Gambar 3. Activity Diagram Karyawan

$$
\text { 4. ERD }
$$

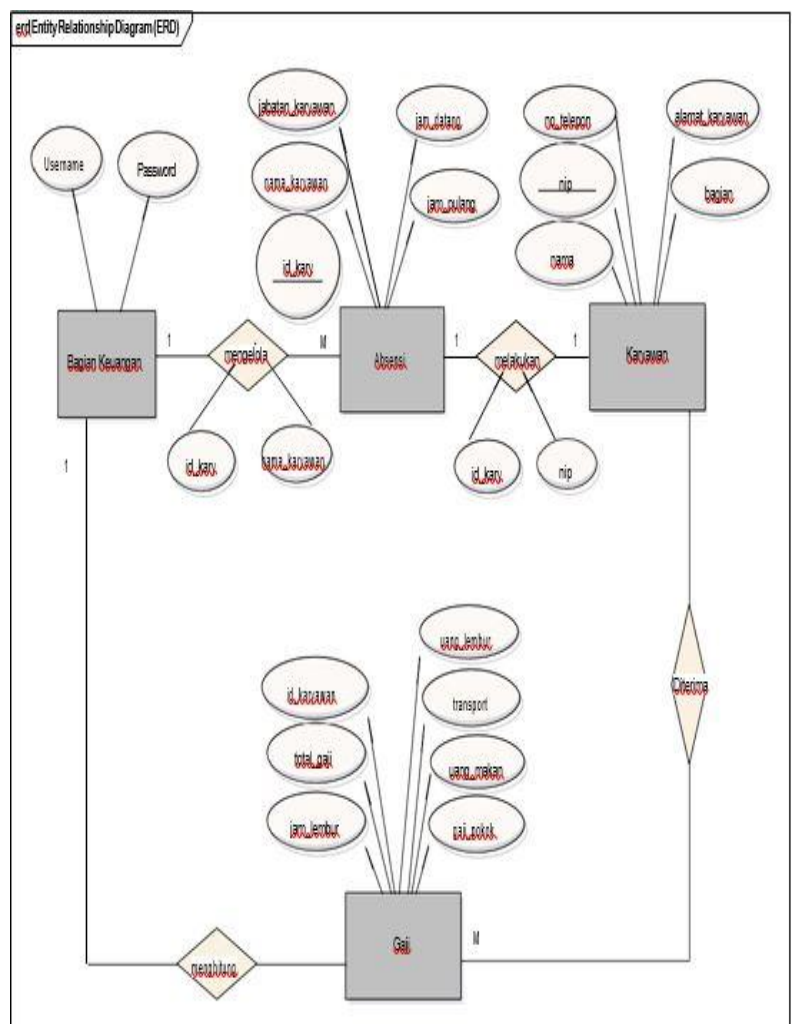

Sumber: Penelitian (2019)
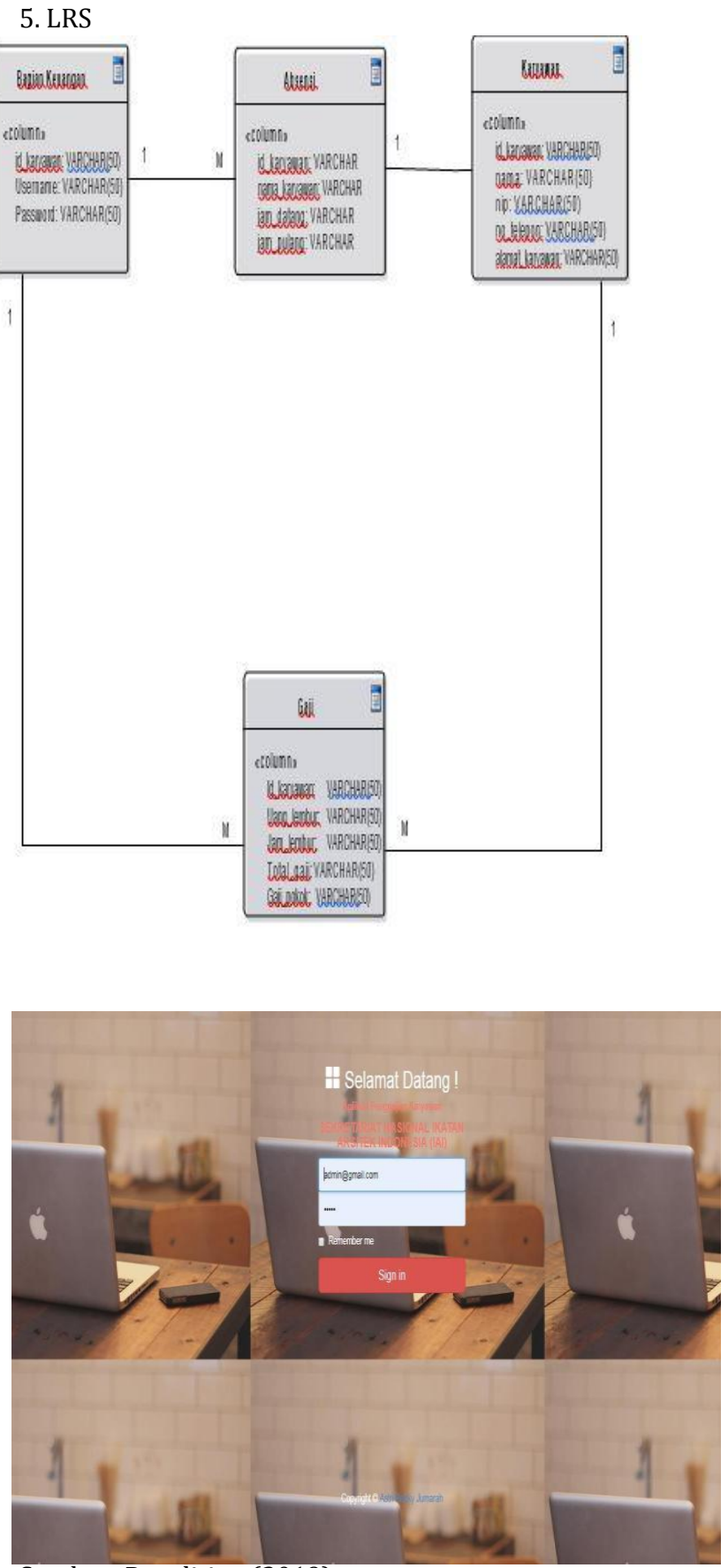

Sumber: Penelitian (2019)

Gambar 6. Login 


\section{Protoype Data Karyawan}

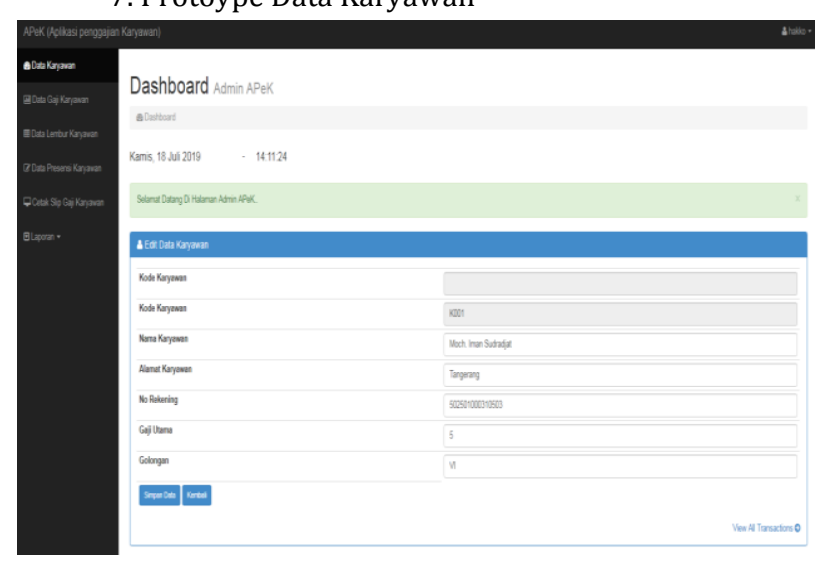

Sumber: Penelitian (2019)

Gambar 7. Data Karyawan

8. Protoype Data Gaji Karyawan

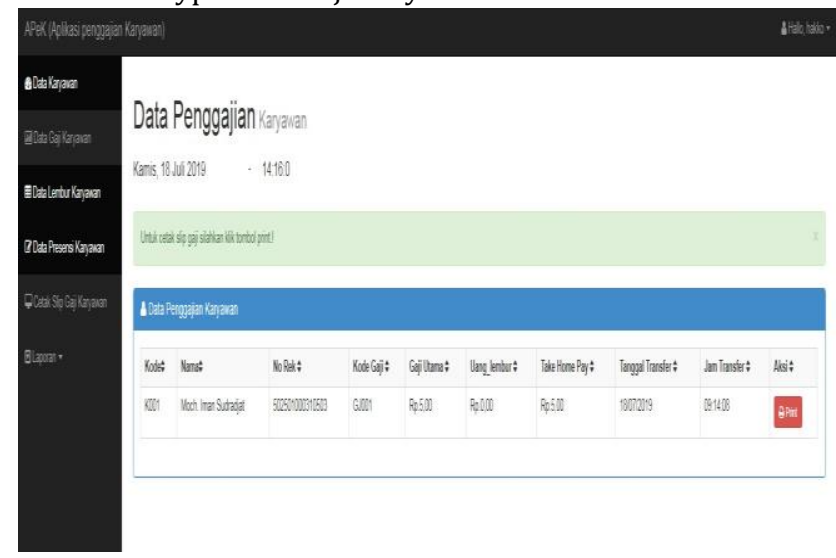

Sumber: Penelitian (2019)

Gambar 8. Data Gaji Karyawan

\section{Protoype Slip Gaji Karyawan}

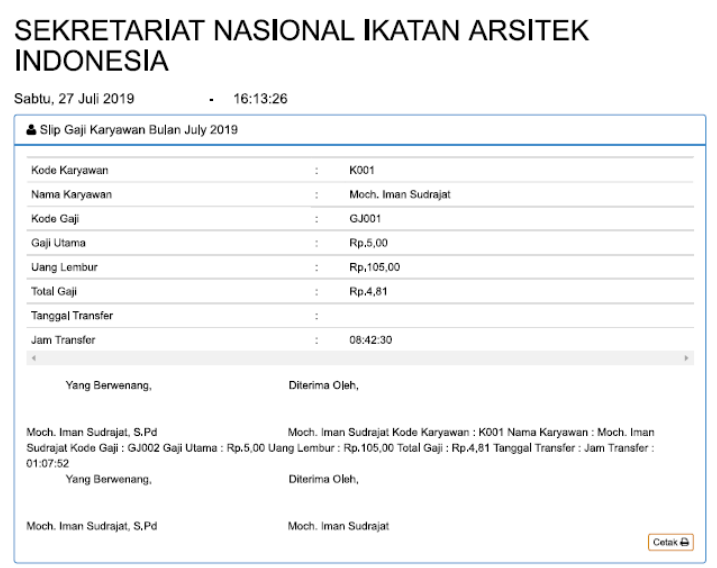

Sumber: Penelitian (2019)

Gambar 9. Slip Gaji Karyawan

\section{KESIMPULAN}

Dari hasil analisis melalui wawancara yang telah dilakukan, diketahui bahwa, sistem penggajian yang berjalan ini masih kurang baik dalam mengolah maupun mengarsipkan gaji sehingga masih kurang efisien cepat dan tepat dalam mengolah data gaji karyawan. Peneliti ingin membuat sebuah aplikasi berbasis web agar penggajian karyawan berjalan secara lancar yang nantinya hasil inputan akan disimpan dalam database agar tidak mengalami kesulitan. Sistem Informasi Penggajian Karyawan pada Sekretariat Nasional Ikatan Arsitek Indonesia diharapkan akan memudahkan setiap inputan dan penggajian karyawan berjalan dengan baik dan benar.

Proses penggajian dan pengarsipan dari yang manual menjadi berbasis website, dimana system berbasis website merupakan system online yang dapat diakses secara langsung oleh karyawan, untuk melihat data gaji karyawan tanpa harus mengunjungi bagian keuangan (admin). Adanya sistem rekap gaji berbasis web ini diharapkan mampu membantu bagian keuangan(admin) untuk mengefisiensi kerja dari kesalahan penghitungan gaji, serta dalam proses pengarsipan juga jauh lebih baik dan mengurangi resiko kehilangan data, karena dapat di backup setiap saat.

\section{REFERENSI}

Danke, Yuanita.(2012).Analisis Perancangan Sistem Informasi Akuntansi Pada Siklus Penggajian dalam Rangka Efektivitas Pengandalian Internal (Studi Kasus Pada Perusahaan Plastik Injection). Jurnal Berkala Ilmiah Mahasiswa Akuntansi,1(1).20-26.

Imaniawan, Fabriyan Fandi Dwi U. M. E. (2017). Sistem Informasi Penjualan Sepatu Berbasis Web Pada Vegas Hyper Purwokerto. Indonesian Journal on Software Engineering, $3(2)$.

Komalasari, A. (2018). Sistem Informasi Akuntansi Penggajian Karyawan Dalam Usaha Meningkatkan Pengendalian Intern Perusahaan. Seminar Nasional Inovasi Dan Tren (SNIT), 2-10.

Puspitasari, D. (2016). Sistem Informasi Perpustakaan Sekolah Berbasis Web. Jurnal PilarNusaMandiri,12(2),227-240. https://doi.org/10.1016/j.advengsoft.201 2.02.001

Rosa A.S. dan M.Shalahuddin. (2015). Rekayasa Perangkat Lunak. Bandung: Terstruktur dan Berorientasi Objek

Yesni Malau,T.A.S.D.W.(2018). Implementasi Slip Gaji Elektronik Pada CV. Mediaku Kreatif ( Motion Production). Jurnal Swabumi, 6(1), 8-17. 
